\title{
A REINVENÇÃO DA QUADRA: O PLANO DE QUADRA COMO ALTERNATIVA DE CONTROLE E DESENHO URBANO
}

\author{
LA REINVENCIÓN DE LA CUADRA: \\ EL PLAN DE CUADRA COMO ALTERNATIVA DE CONTROL Y DISEÑO URBANO
}

\author{
THE REINVENTION OF URBAN BLOCK \\ THE URBAN BLOCK PLAN AS AN ALTERNATIVE OF CONTROL AND URBAN DESIGN
}

\section{MEDINA, LUCIANO LACERDA}

Doutor em Desenvolvimento Urbano, Professor Adjunto do Departamento de Arquitetura e Urbanismo da UFPE, Il.medina@globo.com

\begin{abstract}
RESUMO
A produção de espaço urbano no Recife apresenta evidências de uma inversão entre a dimensão pública e a dimensão privada. Isto está relacionado com problemas entre a forma urbana resultante da interface dos edifícios privados e espaços públicos, assim como pelas características e usos destes edifícios determinados pelo mercado imobiliário. Tal situação vem contribuindo para uma perceptivel falta de animação urbana em muitas ruas da cidade. Assim, avaliamos, à luz das atuais condições de produção de espaço urbano do Recife, um instrumento de controle e desenho urbano já utilizado pelo Planejamento Urbano Municipa em meados do Século XX: o chamado Plano de Quadra. De sua aplicação resultaram referenciais significativos de morfologia e tipologia localizados no Centro do Recife e em alguns Centros de Bairros. Na atual crise da produção de espaço urbano, no Recife, esse instrumento apresenta indícios de que poderia novamente contribuir para melhoria da relação entre o público e o privado, entre morfologia e tipologia. Deste modo, procuramos estabelecer as condições atuais e contemporâneas de formatação, de regulação e de parâmetros de desenho para a viabilidade do que chamamos de Plano de Quadra Condominial-Comunitário ou Comunidade de Quadra.
\end{abstract}

PALAVRAS-CHAVE: desenho urbano; arquitetura urbana; plano de quadra.

\section{ABSTRACT}

The production of urban space in Recife presents evidences of an inversion between the public dimension and the private dimension. This is related to problems between the urban form resulting from the interface of private buildings and public spaces, as well as the characteristics and uses of these buildings determined by the real estate market. This situation has contributed to a noticeable lack of urban animation on many of the city's streets. Thus, we evaluated, in the light of the current urban space production conditions of Recife, an instrument of control and urban design already used by Municipal Urban Planning in the middle of the 20th Century: the so-called Urban Block Plan. Its application resulted in significant references of morphology and typology located in the Center of Recife and in some Neighborhood Centers. In the current crisis of urban space production in Recife, this instrument shows signs that it could once again contribute to an improvement in the relationship between the public and the private, between morphology and typology. In this way, we seek to establish the current and contemporaneous conditions of formatting, regulation and design parameters for the feasibility of we call the Condominium-Community Urban Block Plan or Community Block. KEYWORDS: urban design; urban architecture; urban block plan

\section{RESUMEN}

La producción de espacio urbano en Recife presenta evidencias de una inversión entre la dimensión pública y la dimensión privada. Esto está relacionado con problemas entre la forma urbana resultante de la interfaz de los edificios privados y espacios públicos, así como por las características y usos de estos edificios determinados por el mercado inmobiliario. Esta situación viene contribuyendo a una perceptible falta de animación urbana en muchas calles de la ciudad. Así, evaluamos, a la luz de las actuales condiciones de producción de espacio urbano de Recife, un instrumento de control y diseño urbano ya utilizado por la Planificación Urbana Municipal a mediados del siglo XX: el llamado Plan de Cuadra. De su aplicación resultaron referenciales significativos de Morfología y Tipología ubicados en el Centro de Recife y en algunos Centros de Barrios. En la actual crisis de la producción de espacio urbano, en Recife, ese instrumento presenta indicios de que podría nuevamente contribuir para mejorar la relación entre lo público y lo privado, entre morfología y tipología. De este modo, buscamos establecer las condiciones actuales y contemporáneas de formato, de regulación y de parámetros de diseño para la viabilidad de lo que llamamos Plan de Cuadra CondominialComunitario o Comunidad de Cuadra.

PALABRAS CLAVE: dibujo urbano; arquitectura urbana; plano de cuadra. 


\title{
1 INTRODUÇÃO: UMA FENOMENOLOGIA SOBRE A PRODUÇÃO DE ESPAÇO URBANO NO RECIFE
}

Falando de imaginação, poderíamos pensar que se trata de subterfúgio ou que se trata de produzir coisas extraordinárias. Ao contrário, evidência nos leva a considerar preferencialmente a realidade tal como ela é. A ideia do título - que não deixa de cultivar o paradoxo - fala sobre a riqueza que pode haver em considerar a realidade. É assim que eu o compreendo (...) Hoje precisamos redescobrir a estranheza mágica e a singularidade das coisas evidentes (SIZA, 2012, p.139/140; grifo do autor).

Este artigo constitui parte de uma Tese de Doutoramento (MEDINA, 2018) que assumiu sua dimensão empírica, como seria própria à prática projetual arquitetônica e urbanística e, portanto, foi proposta como de dimensão fenomenológica, entendendo-se que:

\begin{abstract}
A fenomenologia é o estudo da experiência humana e dos modos como as coisas se apresentam elas mesmas para nós e por meio dessa experiência (...). A fenomenologia reconhece a realidade e a verdade dos fenômenos, as coisas que aparecem. Não é o caso, como a tradição cartesiana teria nos feito crer, que "ser um retrato" ou "ser um objeto percebido" ou "ser um símbolo" está só na mente. Eles são modos nos quais as coisas podem ser. O modo como as coisas aparecem é parte do ser das coisas; as coisas aparecem como elas são, e elas são como aparecem (SOKOLOWSKI, 2012, p.10-23).
\end{abstract}

Portanto, a prática projetual arquitetônica ou urbanística é fenomenológica. Trata da realidade como ela se apresenta e, por processos analíticos, tenta alcançar a essência do problema e, por suas evidências, propor uma solução numa síntese formal. Neste sentido a tese teve uma dimensão propositiva, como um projeto, todavia, a sua dimensão analítica foi mais extensa e aprofundada ${ }^{1}$.

No processo projetual, imaginar as evidências é da práxis, mas de visão pessoal do arquiteto, porém, apresentar todas as evidências através de uma tese é fundamental, conforme indica o diálogo reproduzido por Siza em seu livro Imaginar a evidência.

- Você disse um dia "A síntese precede a análise".

- Se eu disse isso, então devo retificar (...) Também não disse o contrário: que a análise precede a síntese. Tenho o hábito de falar do vai e vem: fazemos ziguezagues porque a síntese absoluta não pode ser dosada como um método. O desenvolvimento de um projeto é sempre um equilíbrio entre as duas posições: conhecimento, análise e sensibilidade (...) Quanto à ideia de síntese, com tudo o que ela induz de completo, de global, de absoluto, é uma forma que inclui, que força mesmo a oportunidade de análise. Para que, de um absoluto, tenhamos consciência de que o que fazemos é parcial (SIZA, 2011, p.152 grifo do autor).

As legislações transformaram-se, desde meados do Século XX, no único instrumento de desenho urbano do Recife. A despeito de uma ou outra tornarem-se mais complexas em alguns de seus parâmetros. São os coeficientes de utilização, taxas de ocupação, percentual de solo natural, exigências de vagas de garagem que têm desenhado o espaço urbano do Recife há muito tempo. Desenham a tipologia dos edifícios e a morfologia ${ }^{2}$ de quadras e bairros indistintamente daquilo que é público ou privado, ao contrário do passado. E uma parte da cultura urbana ${ }^{3}$ do Recife - especialmente a do Mercado Imobiliário - tem 'endossado' essa prática de desenhar por parâmetros matemáticos indistintamente.

Um tipo arquitetônico que chamamos de Torre/Pódio ${ }^{4}$ é a síntese formal de todos esses parâmetros matemáticos de desenho. Tornou-se um modelo arquitetônico ${ }^{5}$ de repetição (Figura 1 ) na produção de espaço urbano. Os parâmetros de desenho urbano pensados para esse tipo, desenham qualquer edifício, seja privado ou público, no Recife.

Figura 01: Croquis ilustrativo da LUOS 14.511/83 definindo o Tipo Torre/Pódio

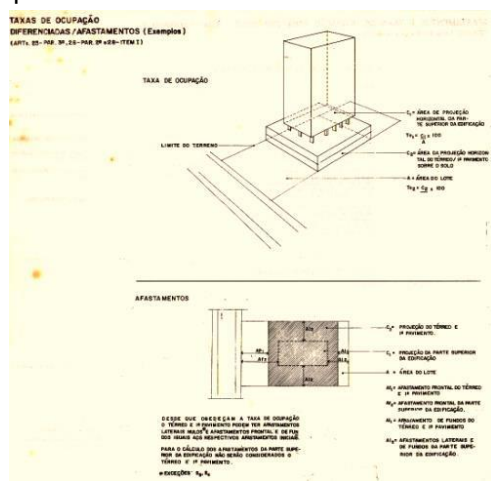

Fonte: Prefeitura da Cidade do Recife, Lei de Uso e Ocupação do Solo (PCR/LUOS 14.511/83) 
Quando a Revolução Francesa criou a figura do Estado Republicano, novos programas surgiram para demandar novas Arquiteturas. A cidade começou a mudar com o aumento dos vazios que se introduziram em sua forma tradicional (SECCHI, 2006; HOLSTON, 1993). Mas a estrutural relação entre o público e privado permaneceu, até porque os novos programas pertenciam à dimensão pública da cidade. A dimensão privada se mantinha ainda como fundo para os elementos primários, monumentos e espaços públicos (ROSSI, 1995) - relação milenar que pode ser sintetizada do desenho de Hipódamo para as reformas de Mileto (Figura 2).

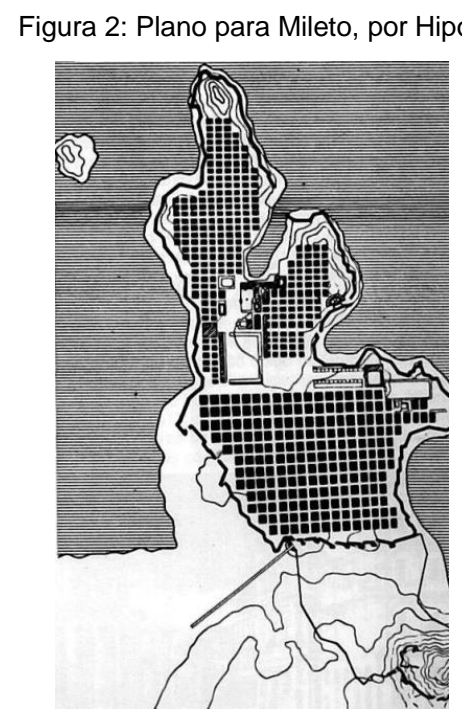

Fonte: SANTOS (1984, p.105).

\begin{abstract}
A Revolução Industrial fez mudar dimensionalmente a estrutura da Cidade-Tradicional (HOLSTON, 1993) e surgiu a Cidade-Pós-Liberal ou a Cidade Moderna (BENÉVOLO, 1987). Esta trouxe com as mudanças tecnológicas grandes equipamentos urbanos - não apenas públicos, mas também privados. As grandes lojas de departamentos são um exemplo de como a dimensão privada avultou-se e também assumiu um pouco da dimensão pública. A própria habitação tomou novas escalas em termo de verticalização para abrigar as grandes massas de pessoas.
\end{abstract}

Apesar dessas mudanças, a cidade continuou mantendo-se dentro daquela estrutura relacional entre público e privado. Sempre rebatida em outras categorias relacionais da realidade urbana-arquitetônica: aberto e fechado, construído e não-construído; até que a proposição da Cidade Modernista rompeu com isso. A exacerbação do vazio, do não-construído, na Cidade Modernista, foi de tal monta que a dualidade entre público e privado não mais foi possível de se reconhecer. Os edifícios estavam 'soltos' num grande 'parque' e não definiam limites. Não fechavam e nem abriam perspectivas. Os edifícios estavam livres das amarras de lotes, quadras, ruas e da própria ideia tradicional de cidade. Os edifícios estavam livres da relação entre público e privado, na Cidade Modernista. A dimensão privada estava restrita ao interior das unidades residenciais e de trabalho. Todo o resto era público.

As 'vantagens' propagandeadas da Cidade Modernista eram a abundância de luz e ar puro, em razão dos afastamentos entre edifícios e do funcionamento organizado da cidade através do zoneamento das funções de habitar, trabalhar e se divertir. A grande 'vantagem' da Cidade Modernista era a de não parecer uma cidade. Isso seduziu arquitetos, urbanistas e planejadores por todo o mundo. Mas como implementar essas ideias nas cidades existentes, sem que necessariamente se desapropriasse todo o solo urbano? Através da operacionalização e uso de ideias híbridas.

Em dissertação de Mestrado cunhamos o termo hibridismo para designar a prática de adaptação de ideias urbanísticas à realidade. Lamas (1992) elaborou outro termo muito similar quando identificou práticas de adaptação dos urbanistas portugueses e europeus no meado do Século XX, na Europa. Ele chamou isso de Urbanismo Operacional.

Os estudos de Gropius sobre construção verticalizada e insolação - determinando afastamentos progressivos à medida que se elevasse o edifício - foram parametrizados em fórmulas matemáticas e 
permitiram operacionalizar um híbrido entre uma ideia de cidade sem parcelamento - utópica - e a realidade das cidades dotadas de lotes.

$\mathrm{Na}$ Europa, grandes terrenos nas periferias das grandes cidades serviram para implantar a paisagem de torres soltas - para habitação -, mas no Recife, as torres soltas foram implantadas em tecidos urbanos consolidados em razão dos afastamentos parametrizados para os lotes. Muito embora, as periferias também tenham recebido grandes conjuntos habitacionais em ressonância com as ideias Modernistas.

O hibridismo ou a operacionalização das ideias não são intrinsecamente atitudes negativas. Lamas evidencia isto ao descrever a elaboração do Plano de Expansão de Barcelona em meados do Século XIX. Ele referencia Cerdá como o criador do Urbanismo por ter elaborado e organizado uma série de passos metodológicos de análise empírica - sociológica, econômica, cultural - sobre a cidade de Barcelona.

Lamas reconhece a dimensão empírica que constituiu a gênese do Urbanismo. Assim, em coerência com a concepção de Lamas, o Urbanismo teria sido originado por operacionalidade. Mas, Lamas diz que a dimensão da qualidade da proposta de Cerdá sobressai-se à dimensão da quantidade (ROSSI, 1995; ARGAN, 1998), portanto, estaria acima do que ele destacou como Urbanismo Operacional. Porém, o próprio Cerdá tentou, também, implantar um híbrido entre a Cidade-Tradicional e a Cidade Moderna ao propor originalmente quadras abertas.

Porque o trabalho de Cerdá com sua estruturada dimensão empírica possui qualidade? Provavelmente, por que Cerdá procurou 'entender' mais sobre o problema da realidade (SIZA, 2011). A dimensão analítica do trabalho de Cerdá foi estendida a ponto de poder constituir uma base empírica e teórica. O hibridismo ou a operacionalidade não significam uma atitude negativa, se, pelo menos, for reconhecida e entendida a realidade. Mas não tem sido esta a prática do Planejamento Urbano, no Recife, nas últimas décadas.

O Planejamento Urbano Municipal, através da legislação urbanística, evidencia que não tem sido considerada de modo pleno a relação entre tipologia e morfologia. A primeira já não desenha a segunda e esta não influi sobre a primeira. A repetição quase à exaustão da Torre/Pódio, por mais de trinta anos, comprova isso. Refletindo e observando a relação entre a dimensão pública e privada na cidade do Recife, percebemos como isso pode está resultando em uma espécie de 'desertificação' de ruas em alguns bairros da cidade (Foto 1), especialmente onde predominam as Torres/Pódios.

Foto 1: A Torre/Pódio e a desertificação das ruas

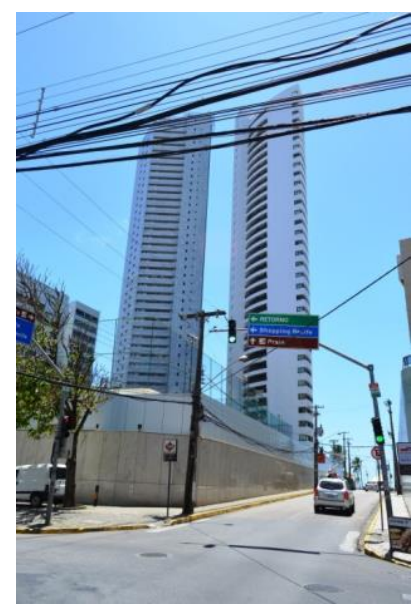

Fonte: Foto do Autor (Out/2017)

A animação urbana ${ }^{6}$, uma dimensão de qualidade sociológica, antropológica e cultural da cidade, evidenciada por Jacobs, vai se tornando escassa no Recife. Isto, talvez seja o último estágio para a consolidação da prevalência da dimensão privada sobre a pública, no Recife.

Animação urbana sustentada ao longo de todo um dia só é evidentemente percebida, no Recife, no seu Centro e em alguns Centros de bairros como Encruzilhada, Afogados, Casa Amarela ou em comunidades de baixa renda como DETRAN, Monsenhor Fabrício, Santa Luzia. Nessas localidades percebem-se características morfológicas comuns, tais como, vias de importância que suportam transporte público, calçadas mais largas - nos espaços formais -, uso comercial e de serviços abundante e uma tipologia baseada no tipo edifício de uso misto.

A legislação urbanística reconheceu essas características morfológicas das chamadas áreas de Centros, em recentes edições, porém, não as incentiva a serem utilizadas extensivamente como a Torre/Pódio. 
O Planejamento Municipal definiu, uma vez, em legislação, a práxis do desenhar como instrumento de controle urbano, quando estabeleceu o redesenho de quadras do Centro do Recife e áreas do que denominou Centros Secundários de bairros entre as décadas de 50 e 70 do Século XX7.

A ideia do redesenho de quadras do Centro do Recife e de bairros era formatar a cidade em acordo com as ideias do plano do professor Baltar para um Recife Metropolitano ${ }^{8}$. Através do micro desenho urbano de quadras, pretendia-se desenhar partes do Recife. Nesse desenho, a dimensão privada e extensa de bairros teria parâmetros matemáticos e genéricos de desenho e destacaria, como um fundo, o Grande Centro da cidade e os seus Núcleos Urbanos ${ }^{9}$, e estes seriam desenhados especificamente como num projeto.

Os Centros fariam o papel de elementos primários ou de monumentos e o restante das áreas da cidade o papel da área-residência (ROSSI, 1995). A altimetria da Cidade-Tradicional foi monumentalizada pela verticalização dos tipos Modernistas - operacionalizados em edifícios de uso misto - com a intenção de configurar os Centros numa espécie de Arquitetura de Dimensão Urbana e numa Cidade de Dimensão Arquitetônica. A despeito das intenções de monumentalização e das implicações que isso incorreria no futuro - como a destruição de patrimônio arquitetônico memorial - o Planejamento Urbano Municipal operacionalizou um híbrido entre a Cidade-Tradicional e a Cidade Modernista com o desenho de Planos de Quadras para o Centro do Recife. O que resultou em alguns exemplares de tipologia e morfologia que ainda sustentam animação urbana por permitir alternativas de mobilidade por entre quadras.

O que os Planejadores não contavam era o que ocorreria com a área-residência de Boa Viagem. Como uma área de expansão urbana completamente propícia ao novo, - através do extenso uso da Torre/Pódio - constituiu-se em mais do que um Núcleo Urbano idealizado por Baltar (1951), tornou-se a nova centralidade metropolitana do Recife (Foto 2).

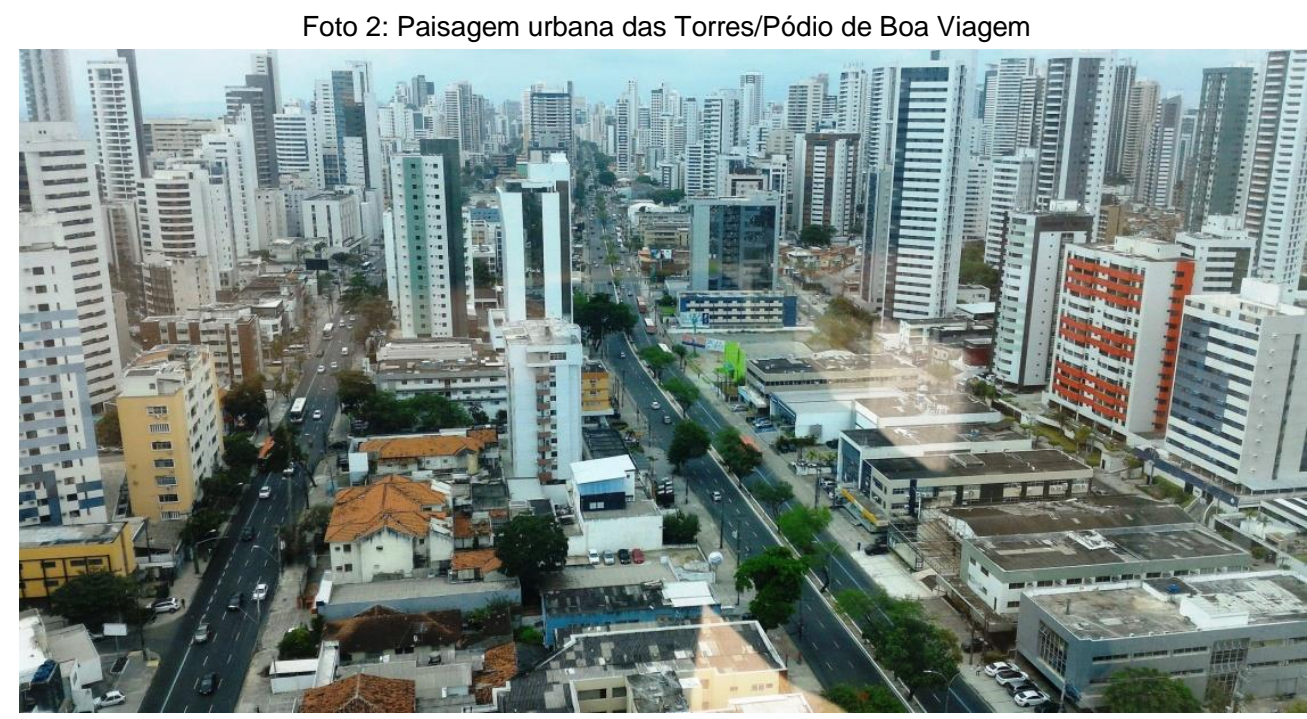

Fonte: Foto do Autor [Abr/2017]

Pelas evidências apresentadas na observação fenomenológica sobre o desenho e a produção de espaço urbano no Recife e seu problema de inversão entre o público e o privado - ocasionado por problemas entre morfologia e tipologia — , agravado pela falta de animação urbana que, agora, se estende por ruas e bairros da cidade, elaboramos a nossa Tese, entendendo ser necessário evidenciar - ou retomar - outra alternativa de produção de espaço urbano no Recife.

Numa análise morfológica-fenomenológica sobre a produção de espaço urbano no Recife, apresentamos evidências de como as legislações urbanísticas e o Planejamento Urbano local constituíram uma das facetas de identidade do problema-fenômeno (entendida conforme definição de SOKOLOWSKI, 2012). Para isso atualizamos, editamos e complementamos nossas análises - iniciadas em dissertação de Mestrado de 1996 - sobre as Leis de Uso e Ocupação do Solo, incluindo três novos instrumentos de controle que surgiram desde 1996 — as Leis de números 16.176/96; 16.719/01 e a 17.511/08 ${ }^{10}$ da Prefeitura da Cidade do Recife (PCR).

Também, argumentamos sobre o que chamamos de cultura urbana do Recife - como elemento de sustentação da produção da Torre/Pódio há mais de 30 anos pelo Mercado Imobiliário. Cultura urbana que 
expressaria, em parte, a relação das pessoas com as legislações urbanísticas e o espaço urbano favorecendo o que se tornou prática comum no Mercado Imobiliário na produção e consumo das Torres/Pódios. Obviamente, não se tratando de uma tese antropológica, sociológica não estruturamos uma fenomenologia da cultura urbana do Recife.

Porém isso nos levou a abordar alguns ensaios críticos sobre uma suposta herança cultural brasileira de aversão ao espaço público ${ }^{11}$. Esses ensaios e suas hipóteses sobre 'uma cultural aversão do brasileiro ao espaço público', se considerados a termos, traria, em seu bojo, a conclusão da irreversibilidade do que hoje acontece no espaço urbano do Recife e até em outras cidades brasileiras. Todavia, alguns espaços urbanos do Recife - o Centro, os Centros Secundários de bairros, comunidades de baixa-renda - não parecem confirmar isso plenamente. São espaços urbanos que apresentam uma relação próxima entre público e privado, onde morfologia e tipologia se relacionam para sustentar uma cultura urbana de vivência do espaço público. Isso ocorre em razão da forma projetada do espaço, de sua ocupação, de algumas características de apropriação e uso? O espaço pode moldar a cultura urbana ou ele é apenas uma representação desta?

Por meio de medições instrumentais, a Neurociência - campo de pesquisa em medicina e biologia aplicado ao comportamento humano - tem comprovado a influência do espaço arquitetônico construído sobre o cérebro humano, vinculando-a às condições de luminosidade, texturas, geometria, o que os arquitetos, filósofos e críticos de Arquitetura sempre tentaram provar através dos seus trabalhos. Isso faz crer que ao espaço arquitetônico e urbanístico e sua forma, talvez, ainda caiba a potencialidade de criar ou moldar cultura urbana. Assim, aquelas hipóteses sobre uma histórica e cultural aversão ao espaço público do brasileiro, entendemos, não apontam para a uma condição plenamente irreversível.

Em razão disso tudo a avaliação deste instrumento de desenho urbano consistiu de: (i) uma análise fenomenológica e morfológica sobre a atual produção e desenho do espaço urbano do Recife visando ressaltar as componentes de identidade do problema; (ii) de uma fundamentação empírica e teórica para evidenciar como tipologia produz morfologia e vice-versa; do cruzamento entre essa fenomenologia urbana e a fundamentação (itens anteriores); (iii) extrapolar características morfológicas e tipológicas contemporâneas para o Plano de Quadra; (iv) utilizar simulações e experimentações em quadras do espaço urbano do Recife a fim de avaliar, pela prática, essa alternativa de controle e desenho urbano.

$\mathrm{Na}$ atual crise da produção de espaço urbano, no Recife, o Plano de Quadra - ou mesmo a Quadra como elemento mínimo e básico de Planejamento e Desenho Urbano - apresentou evidências de que pode contribuir para melhoria da relação entre o público e o privado, entre morfologia e tipologia. Isto, se esse instrumento for adequadamente formatado, disponibilizado e regulado. Nele os limites de parcelamento das quadras não precisariam ser considerados. Os direitos de propriedades dos lotes continuariam a ser exercidos sob a forma de gestão condominial — como já é prática do Mercado Imobiliário aceita pelos seus consumidores.

Deste modo, a tese buscou estabelecer as condições contemporâneas de formatação, de regulação e de parâmetros de desenho para a viabilidade do Plano de Quadra à luz de uma fenomenologia sobre a atual produção de espaço urbano no Recife; este objetivo que será resumidamente trabalhado nesse artigo.

\section{A DIMENSÃO URBANA DA ARQUITETURA E A DIMENSÃO ARQUITETÔNICA DA CIDADE}

Se a essência do problema/fenômeno na produção de espaço urbano no Recife, reside num conflito entre as dimensões pública e privada da cidade, o qual se manifesta por uma relação crítica entre morfologia urbana e tipologia arquitetônica, entendemos que faltaria, então, à Arquitetura do Recife (especialmente a produzida pelo mercado imobiliário) uma dimensão urbana. Tal ausência repercute em espaços públicos (em especial as ruas) que não resultam de uma relação por uso e desenho de seus edifícios e, portanto, não sustentam animação urbana em muitas áreas da cidade com alta densidade habitacional.

Quais seriam os referenciais teóricos e empíricos que poderiam fundamentar a ideia de uma Arquitetura de Dimensão Urbana e de uma Cidade de Dimensão Arquitetônica para o Recife?

Em Carlos Aymonino (1984) e Aldo Rossi (1995) encontramos fundamentos sobre as relações entre morfologia e tipologia, uma relação que não se explica, exclusivamente, pela teoria funcionalista (ROSSI, 1995), pois, segundo este último, a forma dos edifícios e seus tipos e da cidade com suas morfologias são elementos concretos e suficientemente autônomos para explicar o fenômeno urbano.

Em Giulio Carlos Argan (1998) vimos que o espaço urbano pode expressar significados tal qual um objeto artístico. Argan destaca o conceito de qualidade (estético e artístico) e o de quantidade (afeito aos aspectos mais pragmáticos), como um fundo (ou a área-residência como chamou Rossi) que evidencia os espaços e 
edifícios de qualidade, na cidade (Figura 2). Coincidentemente Rossi se vale da mesma nomenclatura sobre essas duas categorias representativas das relações entre morfologia e tipologia.

Por sua vez, Cristian Norberg-Schulz (1983) relaciona a Arquitetura ao seu contexto imediato, e evidencia o potencial de entendimento sobre a visão de mundo das sociedades através da 'leitura' de seus edifícios e espaços urbanos mais importantes: os da qualidade. Assim, Norberg-Schulz aproxima-se de Argan, Rossi e Aymonino no entendimento de que esses edifícios mais significativos contam a história das culturas urbanas em que se inserem. Em acordo com Norberg-Schulz a dimensão urbana da Torre/Pódio caberia apenas à dimensão aparencial da Arquitetura, como objetos para serem apreciados (rever Foto 2).

No que concerne à dimensão cultural da cidade, nada é mais evidente sobre a melhor relação entre morfologia e tipologia do que o movimento de pessoas nos espaços públicos (especialmente a rua), o que Jane Jacobs (200) chamou de animação urbana. Seu objeto de estudo e de ilações foi a concretude do espaço urbano de Nova York/Manhatann e, muito embora Jacobs tenha tratado do aspecto mais antropológico e cultural das cidades, reconhecia o papel da tipologia e da morfologia para constituição de animação urbana; seu conceito tipológico sobre as aberturas dos edifícios como "os olhos das ruas" é um dos mais conhecidos.

No campo da análise morfológica, outro trabalho de muita propriedade é Formas Urbanas - A Dissolução da Quadra, de Philippe Panerai, Jean Castex e Jean-Charles Depaule (2013). Os autores argumentam que o pior das ideias Modernistas sobre cidades não teria sido a intenção da dissolução do parcelamento, nem mesmo querer abolir a propriedade privada, mas sim almejar a dissolução da Quadra. Segundo eles, na Europa, e especialmente na França, a Quadra guardaria o sentido de comunidade. Além disso, para os autores a Quadra desenha a cidade (PANERAI, CASTEX, DEPAULE, 2013) e seria, assim, o último dos elementos morfológicos (LAMAS, 1992) a guardar a ideia e o sentido tradicional de cidade, manifesta na relação entre público e privado.

Numa perspectiva histórica sobre a forma urbana, a concepção de Bernardo Secchi (2006) no seu Primeira Lição de Urbanismo salienta que a ideia do vazio, representada pela figura do jardim, foi responsável por grandes alterações na forma urbana a partir do Século XVIII. Isto é crucial para o entendimento de que a relação entre o público e o privado mudou a partir de então.

Todavia, empiricamente, buscamos referenciais da realidade — mesmo que projetual — para apoiar esse estudo sobre morfologia e tipologia. Organizamos os referenciais elaborados, pensados, projetados como pertencentes ao que chamamos de morfologias da formalidade (Foto 3). Mas, também trouxemos da concretude do espaço urbano do Recife os referenciais das morfologias da informalidade, aquelas que se apresentam pela 'ocupação espontânea' e não planejada, mas que, de algum modo, possuem uma relação entre morfologia e tipologia que sustenta animação urbana.

Assim, uma análise morfológica que realizamos para uma área do Centro do Recife - quando estávamos na Secretaria de Planejamento da Prefeitura do Recife -, objeto de redesenho por Planos de Quadras, constituiu nosso primeiro referencial como representante da formalidade (Foto 3). Esse estudo apresentou evidências sobre formas de apropriação dos espaços das quadras do Centro de modo coletivo e dinâmico - especialmente com mobilidade de pedestres pelo espaço interior das quadras. Animação urbana sustentada por morfologia e tipologia de qualidade. Esse estudo nos apresentou o Plano de Quadra como um instrumento de desenho urbano.

$\mathrm{Na}$ cidade ideal grega fomos buscar as origens da essência da forma urbana na sua estruturação entre público e privado. A cidade como uma configuração de quadras para suporte da dimensão privada e fundo para destaque da dimensão pública (Figura 2). Séculos depois, uma ideia de cidade desenhada por um sistema articulado de quadras, evidenciaria mudanças dimensionais na relação entre público e privado ao propor para o privado a ampliação do vazio - jardins e convívio - numa escala de espaço de natureza semipública. Este foi o Plano de Expansão de Barcelona proposto por lldefonso Cerdá em 1859. Entendemos que na concepção de Cerdá sobre o aumento dos vazios, na dimensão privada, possa estar a gênese da Cidade Jardim de Ebenezer Howard e a Cidade Radiosa de Corbusier. 


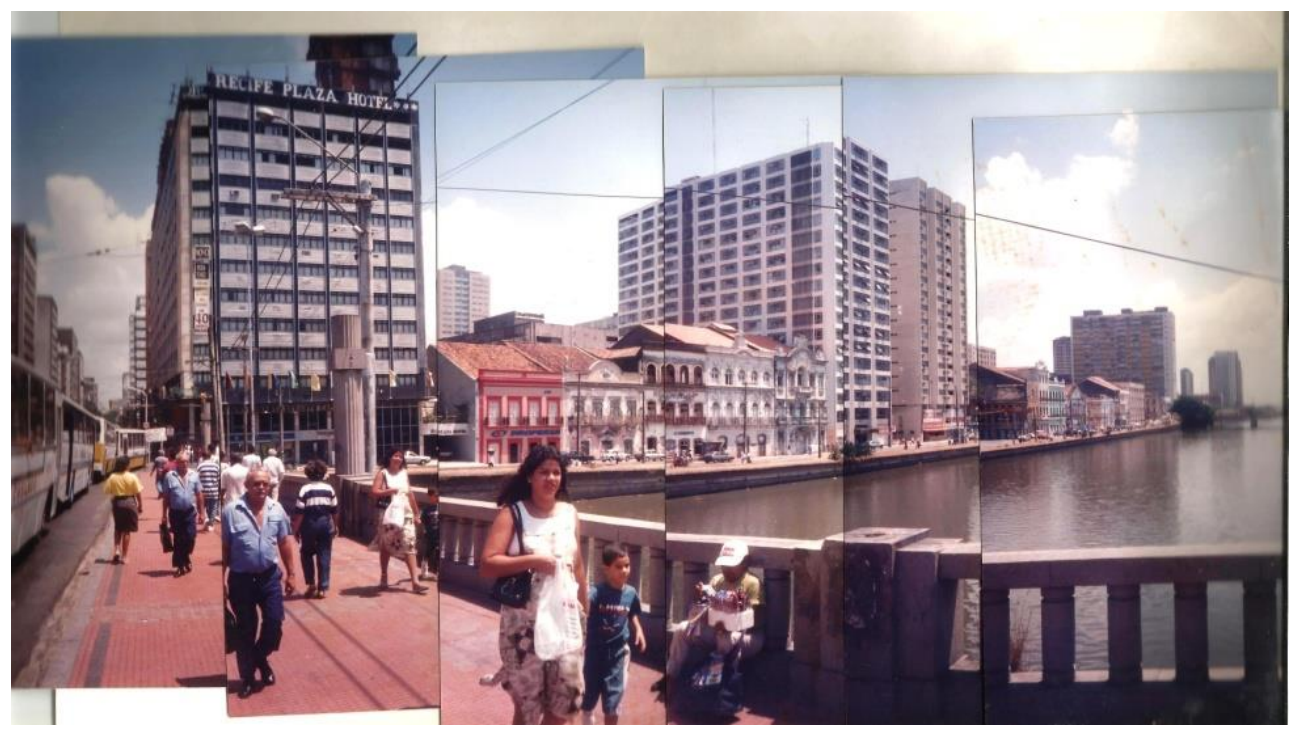

Fonte: Foto montagem do Autor [Jan/1995]

A Quadra, como elemento morfológico (LAMAS, 1992) essencial à forma e significado da cidade, não deixou de ser referenciada, nem mesmo no Plano Piloto de Brasília de Lúcio Costa. O arquiteto brasileiro elaborou um híbrido, na concepção de Brasília, entre a Cidade Modernista e a Cidade-Tradicional. Para a dimensão privada concebeu a ideia das Superquadras. Assim como em Cerdá, as Superquadras constituem uma ideia de espaço comunitário semipúblico. Em Brasília a ideia não foi exatamente a de resguardar a dimensão do privado da dimensão pública. A ideia foi a de criar limites - a Cidade Modernista não os tem - para significar abrigo e espaço humano (HEIDEGGER, 1956).

Para ainda guardar os limites de uma tradição milenar de cidade, representada pela relação entre o público e privado, Christian Portzamparc propôs a Quadra Aberta. Ele entendeu que a quadra seria o 'limite final' para as ideias de desenho urbano sob quaisquer conceitos - fossem a Cidade-Tradicional, a Cidade Moderna ou Liberal, a Cidade Jardim, a Cidade Modernista. A Quadra ainda resguardaria sua função primordial de definir a rua, mas seu interior poderia estar aberto à mobilidade, ao convívio e desprovido de parcelas. A Quadra Aberta de Portzamparc é a proposição de um híbrido para mediar todas as ideias sobre a forma urbana, mantendo a tradicional e estrutural relação entre público e privado - através da Quadra e promovendo uma Arquitetura de Dimensão Urbana e uma Cidade de Dimensão Arquitetônica.

O último representante referencial da formalidade foi o espaço urbano de Manhattan em Nova York. Concebido através de um desenho em grelha de quadras retangulares com intuito de permanecer no tempo sem alterações (BENÉVOLO, 1987), alcançou uma dimensão de apropriação pelas pessoas que lá vivem e a visitam, que a tornou referencial para Jane Jacobs (2000) e que, por sua vez, Rem Koolhas (2008) chamou de delirante, pois o nível de cultura urbana e de aglomeração de experiências e significado é único. Por uma semana caminhamos e fotografamos o distrito de Manhattan e percebemos como a relação entre a morfologia do distrito se relaciona com a sua tipologia, resultando em animação urbana.

Finalmente fomos buscar em algumas comunidades de baixa-renda do Recife - DETRAN, Monsenhor Fabrício e Vila do Vintém - evidências sobre animação urbana em conexão com morfologia e tipologia (Foto 4). Esses referenciais da dimensão da informalidade apresentam em suas morfologias uma cultura urbana que não estabeleceu 'aversão ao espaço público'; apesar de não poderem constituir referencial de qualidade (ROSSI, 1995; ARGAN, 1998). Nesses referenciais percebemos como uma infra-estrutura urbana como um via pública dotada de boa pavimentação e de linha de transporte, quando implantada no interior de uma dessas comunidades, promoveu animação urbana sustentada por transformações tipológicas e morfológicas baseadas na verticalização, densidade e no uso do tipo edifício de uso misto. Percebemos como Manhattan, o Centro do Recife, aqueles Centros de bairros e uma comunidade de baixa-renda como a do DETRAN se assemelhavam em animação urbana decorrente da variedade e mistura de usos, alta densidade e morfologia e tipologia, especialmente calcada no edifício de uso misto e pavimento térreo destinado ao comércio. 


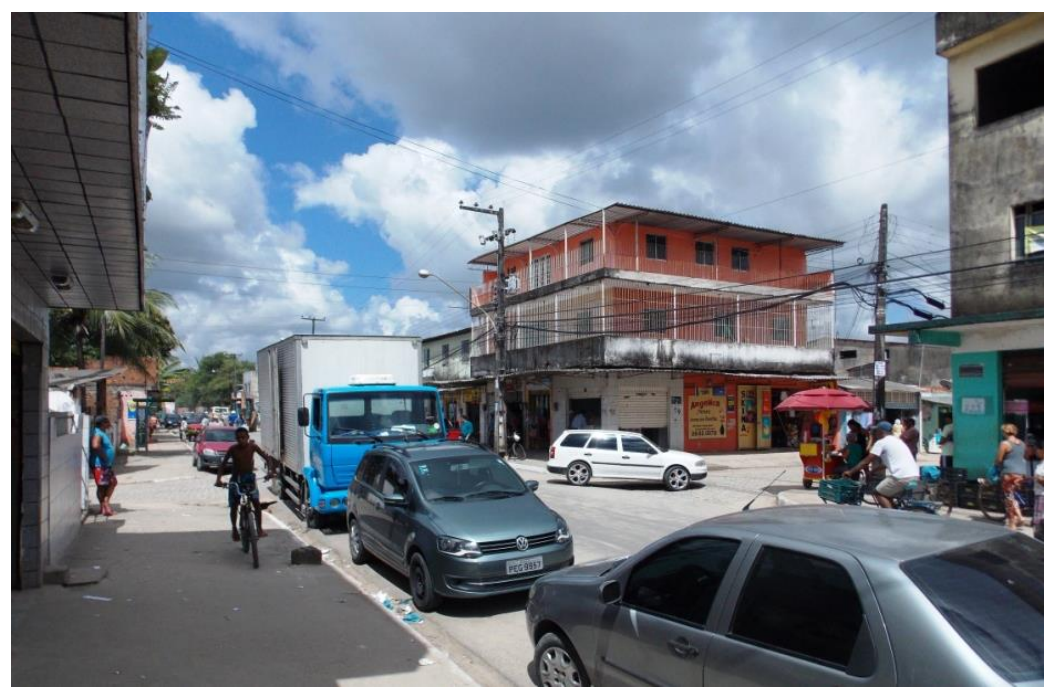

Fonte: Foto do Autor [Out/2013]

\section{REINVENTAR A QUADRA NO RECIFE ATRAVÉS DO PLANO DE QUADRA CONDOMINIAL}

Procuramos fundamentar como a Quadra poderia ser o elemento morfológico básico para o desenho urbano do Recife através do Plano de Quadra, em razão do que acontece hoje na dimensão da formalidade ou da informalidade do Recife e novamente sustentar uma Arquitetura de Dimensão Urbana e uma Cidade de Dimensão Arquitetônica.

Em nosso trabalho, as reflexões, mais que teóricas e empíricas e apoiadas em outros trabalhos e autores ou mesmo na realidade, também, foram construídas a partir do desenhar e projetar morfologia e tipologia.

Nossas experiências de desenho e projetos que ocorreram no Planejamento, na Academia e no estudo sobre o Mercado Imobiliário, também nos ajudaram a alcançar nossos objetivos.

As experiências que empreendemos na prática do Ensino do Projeto e em Concursos de Arquitetura e Urbanismo consideramos mais significativas como referenciais na busca de uma Arquitetura Urbana e de uma Cidade Arquitetônica. Mas, para entender um pouco da cultura urbana do Recife, experiências profissionais anteriores, junto aos 'consumidores' de Arquitetura do Recife, foram importantes para compreender a tipologia que o Mercado Imobiliário produz e, consequentemente, a morfologia resultante. Se a Quadra pode constituir o elemento morfológico básico de controle, desenho e produção urbana, ela ainda continuará suportando os tipos em uso e outros que por ventura vierem a ser criados na implementação de Planos de Quadras.

Assim, extrapolamos o que chamamos de parâmetros culturais de desenho: como os tipos edifício murourbano ou o edifício furo-urbano, o edifício-galeria para variados usos, o edifício-garagem de uso misto; também extrapolamos diretrizes morfológicas como a permeabilidade interna da quadra, aumento dos espaços interiores da quadra para convívio, ocupação perimetral da quadra com pequeno comércio (com o edifício muro-urbano) e imaginamos a formatação de Comunidades de Quadras através da gestão condominial $^{12}$.

Aplicamos esses parâmetros a uma quadra localizada no bairro das Graças para uma primeira avaliação; esse pequeno estudo morfológico serviu como orientação às simulações que realizamos depois, para complementar e finalizar a nossa avaliação (Figura 3).

A partir de então realizamos experimentações de redesenho de quadras a partir de parâmetros vigentes na Lei de Uso e Ocupação do Solo - LUOS (PCR, 1983) - e através de Planos de Quadras, aplicados a 45 quadras de vários bairros do Recife, para comparação. Essas simulações foram realizadas através de uma Disciplina aplicada no 1ํ. Semestre Letivo de 2016 do Curso de Arquitetura e Urbanismo da UFPE. Foram utilizadas bases cadastrais disponibilizadas na internet pela Prefeitura do Recife e outras apoiadas em informações digitais do programa Google Earth. As condições de tempo foram limitantes à extensão dessas simulações. Assim como os recursos tecnológicos de simulação através de imagens de inserção em fotografias da realidade atual ou em maquete digital do Recife do Google Earth. 
A ocorrência de certa dificuldade de elaboração de Planos de Quadras pelos alunos também foi limitante, mas reveladora. As simulações pela LUOS vigente, baseadas em parâmetros matemáticos, eram muito mais 'interativas' em termo de resultados - a participação criativa do 'projetista' era menor. Mas, para os Planos de Quadras as decisões de implantação e volumetrias permitiam variadas alternativas. Isto, por si só, já constituiu uma vantagem em favor do desenho por Plano de Quadra. Neste a dimensão de qualidade é demandante e não consequente, e tomar decisões projetuais de qualidade em curto espaço de tempo é sempre mais complexo.

Figura 3: Montagens sobre foto de esquina de quadra do bairro das Graças com as soluções do o edifício furo-urbano e o edifício muro-urbano para Plano de Quadra
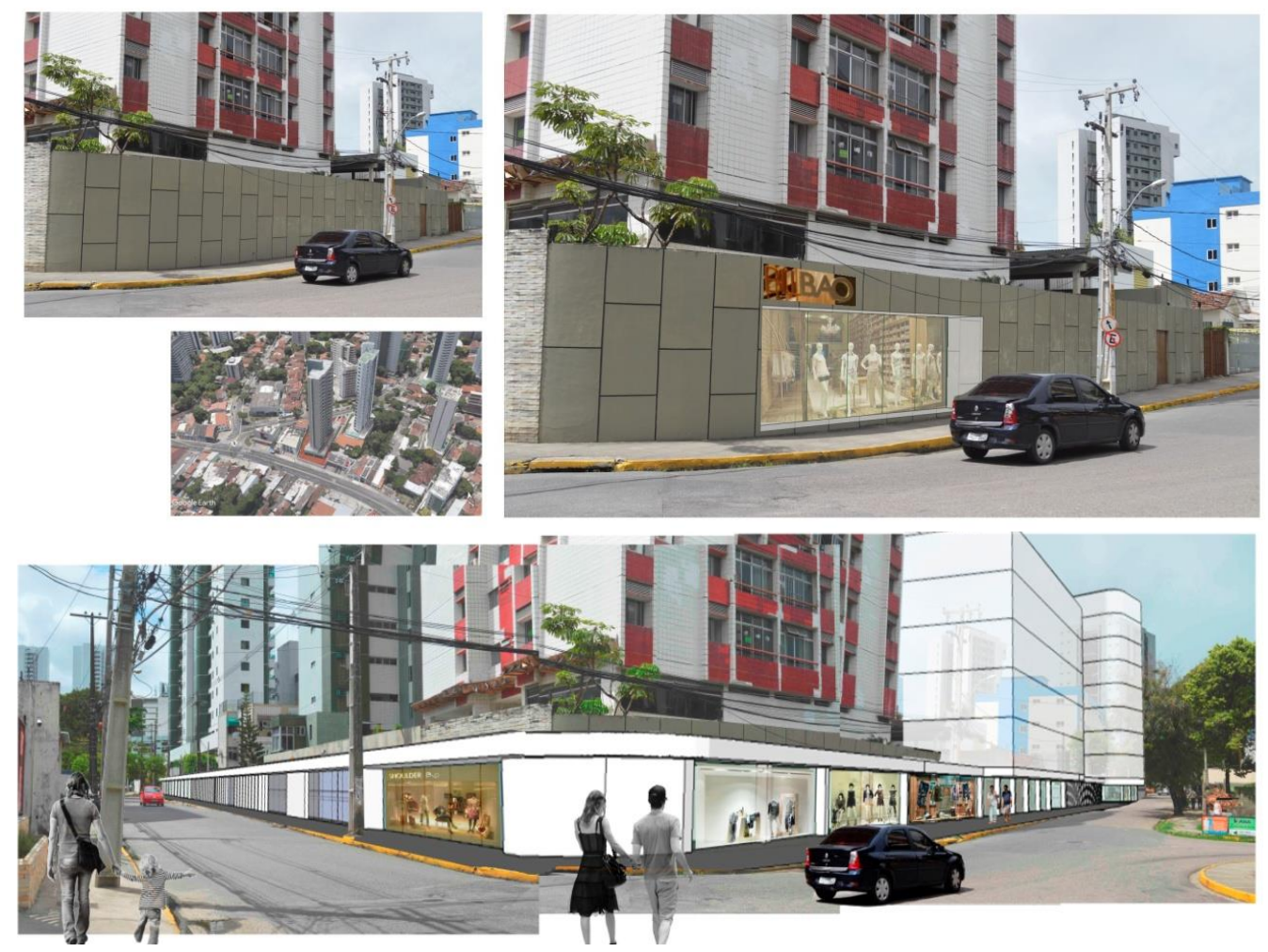

Fonte: Desenhos e foto do Autor (Out/2017).

Figura 4. Simulação de redesenho de quadras no centro do bairro de Afogados, primeiramente através dos requisitos da LOUS e depois por Plano de Quadra

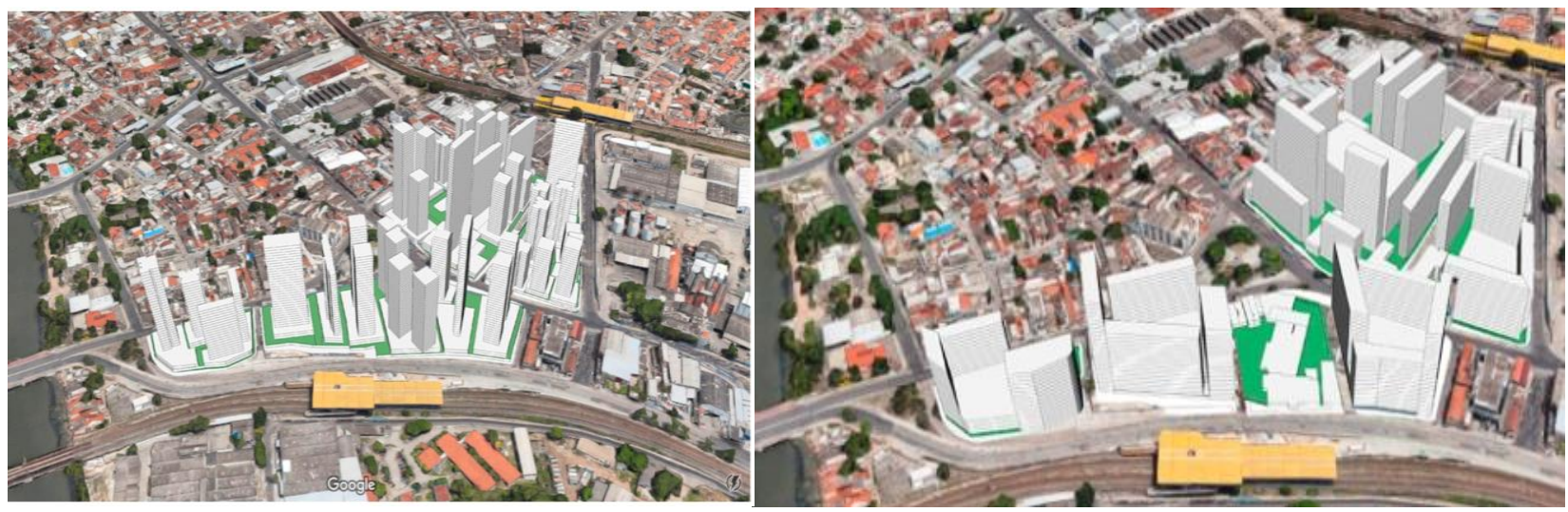

Fonte: Orientação do Autor, desenho da Arquiteta Maria Clara Carneiro [Out/2017]

Descontadas as limitações mencionadas, as simulações foram reveladoras num aspecto inesperado: o da quantidade. A comparação entre algumas soluções elaboradas pela LUOS e Planos de Quadras apontou para um potencial aumento de quantidade em favor do Plano de Quadra, sem que isso afetasse, perceptivelmente, a qualidade.

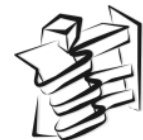


Assim como os levantamentos quantitativos realizados na escala das quadras indicaram, nas simulações pela LUOS, que o coeficiente de utilização não é eficiente para controlar a quantidade de morfologia urbana produzida no Recife, já que os parâmetros matemáticos se limitam ao lote. Se a sua aplicação fosse relativa à Quadra, tais parâmetros poderiam controlar - aumentar, estabilizar e mesmo diminuir - a quantidade de construção da cidade; sempre reivindicada nos momentos de revisão de Lei de Uso e Ocupação do Solo. Isto também demonstra ser a Quadra o elemento morfológico básico e essencial para uma melhor e maior eficiência dos parâmetros de quantidades construtivas na produção de espaço urbano.

\section{CONSIDERAÇÕES FINAIS}

Ao avaliarmos e compararmos um instrumento de desenho urbano como o Plano de Quadra ao da produção por lotes baseada em parâmetros matemáticos de desenho; entendemos que o Plano de Quadra apresentou vantagens de qualidade e potencialmente de quantidade.

O termo Condominial ou Comunitário é relativo à gestão e ao convívio; portanto a denominação de Plano de Quadra Condominial-Comunitário caberia quando da união entre o conceito da forma, gestão e cultura urbana. Mas, se o Plano de Quadra cumprir com todo o seu potencial para proporcionar espaços de vivências e significados, talvez o melhor termo fosse Comunidade de Quadra.

A supressão dos limites dos lotes permitiu desenhar a implantação dos tipos de modo a constituir espaços abertos de potencial uso coletivo - controlados ou não.

Portzamparc (1997) tem razão em considerar que a Quadra seria o último e único elemento morfológico tradicional para resguardar a milenar ideia de cidade - aquela que Hipódamo desenhou. Os limites da Quadra como fronteiras junto às ruas definem os tipos que garantiriam a escala do caminhar (seja por edifícios-galerias, seja pelo muro-urbano), enquanto no seu interior, o uso da ideia Modernista das torres soltas estabeleceriam densidade e outra escala de espaço aberto público ou semipúblico apartado do tráfego de veículos. Todavia, sem a Quadra a cidade perde a sua forma e o seu sentido (PANERAI, CASTEX, DE PAULE, 2013).

Mas, e se a cultura urbana do Recife não reconhecer as vantagens dos Planos de Quadras CondominiaisComunitários?

Elencamos uma série de vantagens que se tornaram evidentes e que as simulações - apesar das limitações - confirmaram. Essas vantagens nos pareceram evidentes porque elas, inclusive, repercutem a cultura urbana do Recife - o desejo por segurança e controle de seus espaços residenciais e de trabalho - sem, contudo, estabelecer refração à animação urbana, necessária ao sentido de urbanidade pelo amplo uso do pequeno comércio junto às calçadas.

Alguns podem não reconhecer na animação urbana do Centro do Recife, dos Centros Secundários de bairros e de uma comunidade como a do DETRAN como referenciais para si mesmos - existe uma desordem aparente. Caberia, talvez, ao Controle Urbano regular essas localidades de modo mais efetivo e encontrar meios e estratégias para incentivar - não apenas determinar e impor - a formação de Comunidades de Quadras, de forma que essas mesmas se auto ajustassem a padrões de qualidade. Pois, o que Ihes falta é apenas isso. Qualidade que só poderá retornar ao espaço urbano do Recife através de tipologia e morfologia que favoreçam usos e atividades variadas ao longo das calçadas e frentes de quadras. O que não pode estar em conflito com o ordenamento de ocupações e o bom desenho de equipamentos - calçadas, mobiliário urbano.

Poderia um Plano de Quadra exacerbar a refração ao espaço público, pela ampliação de muros, controles e reduzindo ainda mais a animação urbana?

Isto seria possível, mas não estaria em acordo com os mínimos parâmetros culturais de desenho que evidenciamos. Um Plano de Quadra destituído de tipos como o edifício muro-urbano-comercial, edifícios furos-urbanos, os edifícios-galerias, os edifícios galerias-garagens, com pouca ou nenhuma variedade de usos e atividades sem estratificação econômica também variada; por certo, seria pior do que se vê hoje, no Recife. Contudo, não se trataria mais da alternativa que foi avaliada.

As mínimas condições de parâmetros culturais de desenho - na forma de tipos e morfologias precisariam ser atendidas. E à medida que um ou mais Planos de Quadras fossem sendo implantados, incorrendo em transformações positivas no espaço urbano do entorno, as necessidades de controle público seriam reduzidas em favor de uma sustentação pela própria cultura urbana. As contradições que, eventualmente, surgissem seriam avaliadas e corrigidas. E o que se espera de um campo disciplinar de forte dimensão empírica - e fenomenológica - como a Arquitetura e o Urbanismo. Além do fato de que 
regulamentado e disponível para uso das iniciativas privadas, o Plano de Quadra teria sua avaliação e acompanhamento enriquecidos por variadas experiências e condições.

Considerar a Quadra como elemento morfológico básico de planejamento, controle, produção e desenho, seria a solução para o problema/fenômeno e as variadas facetas de sua identidade que vimos no Recife?

Não acreditamos em soluções definitivas, por tudo que evidenciamos. Porém, para o Planejamento Municipal, considerar a Quadra como elementar para o controle, produção e desenho de espaço urbano no Recife seria positivo. Isto, inclusive, se ainda mantivesse o controle por parâmetros matemáticos de desenho urbano. Esses parâmetros aplicados aos lotes não controlam eficientemente a intensidade de uso e ocupação do solo. Porém, como estabelecer a Quadra como o elemento morfológico básico, sem que se disponibilize a alternativa de um instrumento de desenho como o Plano de Quadra?

Não seria o edifício de uso misto - especialmente com habitação e comércio - a solução para o problema do espaço urbano do Recife? Uma solução com uso intenso e extenso de um tipo de forte dimensão urbana?

Em se considerando a dimensão de intervenções, construções, envolvimento de interesses e interessados; a resposta seria sim. O edifício de uso misto é uma solução simples, individual e rápida. Contudo, reconhecendo-se uma 'resistência cultural' de mais de trinta anos em relação ao edifício de uso misto; a resposta atual - a da realidade - é não.

O Plano de Quadra Condominial-Comunitário tem o 'apelo' de ser um 'novo conceito' e, por isso, poderia ser até mais fácil o convencimento do Mercado Imobiliário e consumidores. Mas, uma alternativa não exclui a outra, pelo contrário, para um bom Plano de Quadra o uso do edifício de uso misto seria crucial.

Então, a Quadra como unidade básica de planejamento, controle, produção e desenho urbano, através do uso do instrumento do Plano de Quadra Condominial-Comunitário seria a solução para o problemafenômeno da relação crítica entre público e privado, morfologia e tipologia, no Recife?

Novamente, somos obrigados a dizer que não acreditamos em conclusões de soluções definitivas. Uma atividade fenomenológica e de dimensão empírica como a Arquitetura e o Urbanismo não se pode conduzir por certezas, haja vista, lidar com pessoas com seus diferentes e complexos modos de vida produzindo espaços construídos. É possível dizer que a preservação da Quadra, dos seus significados e sua revalorização pelo uso de um instrumento de desenho urbano como o Plano de Quadra é promissor nas atuais condições de produção de espaço urbano do Recife. É uma alternativa disponível ao Poder Público e à iniciativa privada para controlar, desenhar e produzir espaços urbanos onde, novamente, torne-se evidente a melhor relação entre as dimensões do público e privado - com a perspectiva de espaços semipúblicos, inclusive.

É uma alternativa para desenhar outra vez uma Arquitetura de Dimensão Urbana que resulte numa Cidade de Dimensão Arquitetônica.

Assim, destacamos aqui algumas das vantagens desse instrumento de desenho urbano para o Recife:

- Novos parâmetros - culturais - de desenho poderão surgir na escala da quadra: (i) permanências, edifícios significativos que poderão ser preservados por uma simples concordância entre os proprietários e empreendedores; (ii) permeabilidade urbana, definição de novos espaços abertos destinados ao convívio exclusivo dos proprietários e moradores do Plano, ou não, espaços que poderão ser utilizados como sistemas alternativos de circulação; (iii) edifício muro-urbano, um edifício fita que contorna a quadra ou interior dela e define os limites entre o público, semipúblico e privado, poderá abrigar atividades como comércio, equipamentos; (iv) edifício furo-urbano, intervenções pontuais pensadas como maneira de tornar os muros dos Pódios mais amigáveis através de aberturas de pequenos espaços destinados ao comércio; (v) edifício garagem-urbana desenhado especificamente para solucionar os problemas de provimento de vagas aos moradores e trabalhadores do Plano, aos consumidores eventuais, porém o térreo deste edifício será sempre destinado ao comércio e sua cobertura a usos lúdicos ou culturais; (vi) edifício-galeria destinado aos usos mistos, sua arquitetura constitui para o nosso clima verdadeira gentileza urbana; e outros que os empreendedores, arquitetos e planejadores poderão criar.

- O Plano de Quadra Condominial-Comunitário pode ser planejado e desenhado como um 'Bairro Planejado' de menor proporção com a vantagem de que usos e construções já implantados poderão ser aproveitados para integrar e qualificar o ambiente desse 'bairro' diminuto.

- Valorização e difusão dos usos mistos em função da quadra e não apenas em função de lotes ou edifícios, vencendo, aos poucos, a resistência cultural ao edifício de uso misto e reduzindo as necessidades de mobilidade pela proximidade de usos comerciais; vários Planos de Quadras 
Condominiais-Comunitários próximos entre si poderiam criar toda uma nova dinâmica econômica para bairros.

- Aumento da permeabilidade urbana para os pedestres com a possibilidade de se desenhar percursos por entre quadras, criando sistemas alternativos para percursos a pé ou de bicicleta.

- Dinamização do mercado de trabalho de profissionais projetistas, arquitetos, engenheiros, gestores e outros que poderão surgir ou se agregarem em acordo com a aceitação e ajustes a essa alternativa, pois passariam a trabalhar com pequenos planos urbanísticos e não com edifícios isolados.

- O Plano de Quadra Condominial-Comunitário poderá ser constituído de sub-condomínios: o comercial e de serviços, o habitacional, o cultural e outros, organizados, pensados e administrados como o 'mix' dos Shoppings Centers, para garantir a inclusão de usos e atividades com alguma variedade de estratificação socioeconômica.

Para isso, contudo, será preciso realizar a Reinvenção da Quadra no Recife (Figura 5).

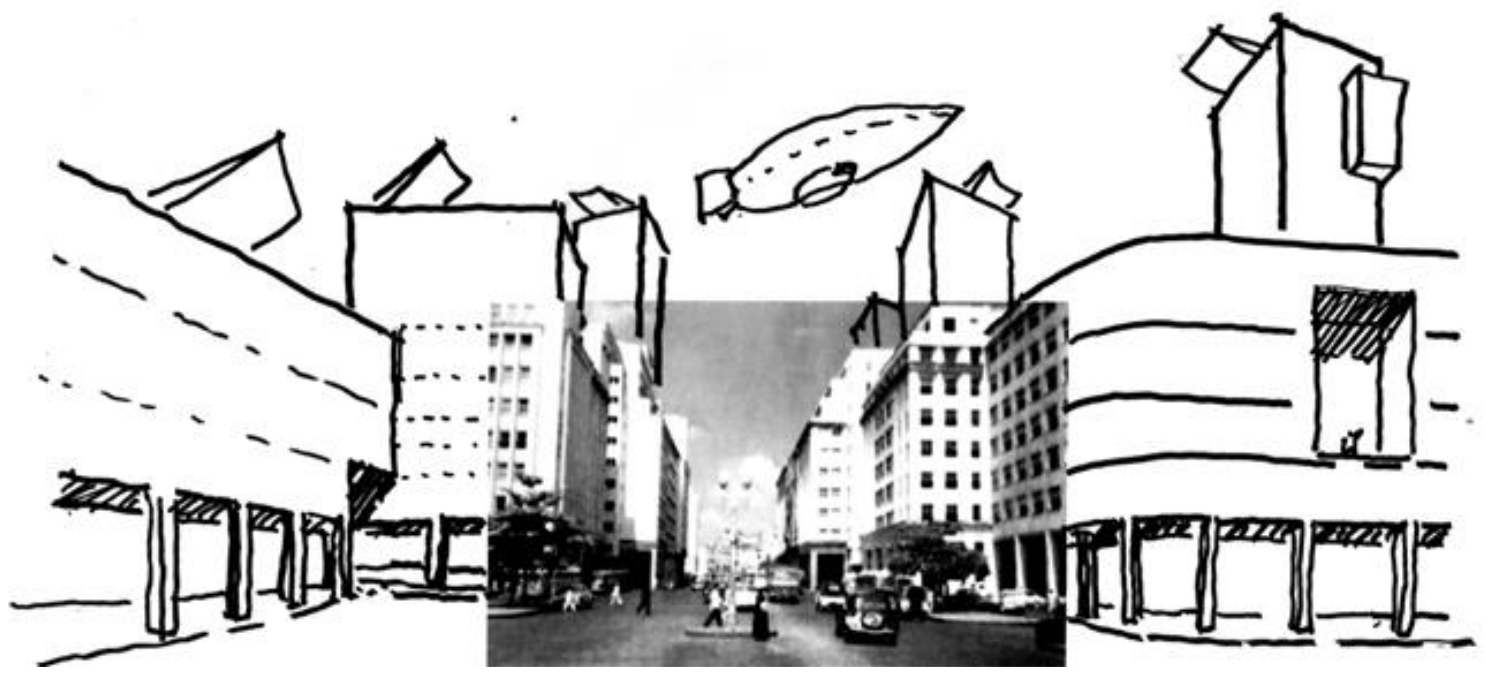

Fonte: Desenho do autor sobre fotografia da Avenida Guararapes de autor desconhecido

\section{REFERÊNCIAS}

ARGAN, G. C. História da Arte como História da Cidade. São Paulo: Ed. Martins Fontes, 1998.

AYMONIMO, C. O Significado das Cidades. Lisboa: Editora Presença, 1984.

BALTAR, A. B. Diretrizes de um Plano Regional para o Recife. Tese de Concurso para cátedra Escola de Belas Artes do Recife, Recife, 1951.

BENÉVOLO, L. História da Cidade. São Paulo: Editora Perspectiva, 1988.

BERTHOZ, A. Les Sens du Mouviment. Paris: Odile Jacob, 1997.

CÂMARA, A. D. Cubierto de Verde y Plantado de Blanco: Las ordenanzas de la Ciudad Moderna, Recife, Brasil. Tese (Doutorado). Universitat Politècnica de Catalunya-UPC. Barcelona, 2013.

CASTEX, J.; PANERAI, P.; DEPAULE, J. Formas Urbanas - A dissolução da quadra. Porto Alegre: Editora Bookman, 2013.

CHOAY, F. A Regra e o Modelo. São Paulo: Editora Perspectiva, 1985.

DaMATTA, R. A casa \& a rua - Espaço, cidadania, mulher e morte no Brasil. Rio de Janeiro: Editora Rocco, 1997.

FERREIRA, M. M.; GOROVITZ, M. A Invenção da Superquadra - O conceito de Unidade de Vizinhança em Brasília. Brasília: IPHAN-DF, 2009.

FREYRE, G. Casa-Grande \& Senzala. Rio de Janeiro: Ed. José Olympio, 1987.

GROPIUS, W. Novarquitetura. São Paulo: Ed. Perspectiva, 1977.

HEIDEGGER, M. Construir, Habitar, Pensar. Vortäge und Aufsäze, G.Neske, Pfullingen,1954. 
HOLANDA, S.B. Raízes do Brasil. São Paulo: Ciia. das Letras, 2014.

HOLSTON, J. A Cidade Modernista - Uma Crítica de Brasília e sua Utopia. São Paulo: Companhia das Letras , 1993.

JACOBS, J. Morte e Vida de Grandes Cidades Norteamericanas. São Paulo: Ed. Martins Fontes, 2000.

KOOLHAAS, R. Nova York Delirante, São Paulo: Cosac Naify, 2008.

LAMAS, J. M. R. G. Morfologia Urbana e Desenho da Cidade. Lisboa: Fundação Calouste Gulbekian, 1992.

LEITÃO, L. Quando o ambiente é hostil - uma leitura urbanística da violência à luz de Sobrados e Mucambos e outros ensaios gilbertianos. Recife: EdUFPE, 2009.

MEDINA, L. L. A Legislação de Uso e Ocupação do Solo do Recife como Instrumento de Desenho Urbano. Dissertação (Mestrado). Programa de Pós-graduação em Desenvolvimento Urbano, UFPE. Recife, 1996.

MEDINA, L. L. A Reinvenção da Quadra - A quadra como elemento de controle e desenho urbano para o Recife. Tese (Doutorado). Programa de Pós-graduação em Desenvolvimento Urbano, UFPE. Recife, 2018.

NORBERG-SCHULZ, C. Arquitectura Occidental. Editorial Gustavo Gilli, Barcelona, 1983.

PANERAI, P.; CASTEX, J.; DEPAULE, J. C. Formas Urbanas - A Dissolução da Quadra. São Paulo: Bookman, 2013.

PORTZAMPARC, C. A terceira era da cidade. Óculum, São Paulo, n.9, (PUC-Campinas), 1997.

PREFEITURA DA CIDADE DO RECIFE (PCR). Lei n. 14.511, que define diretrizes para o uso e ocupação do solo, e dá outras providências (Lei de Uso e Ocupação do Solo - LUOS). Recife: PCR, 1983.

ROSSI, A. A Arquitectura da Cidade. Lisboa: Ed. Martins Fontes, 1995.

SANTOS, C.N. A Cidade como um Jogo de Cartas, São Paulo: Projeto Editores,1984.

SECCHI, B. Primeira Lição de Urbanismo. São Paulo: Perspectiva, 2006

SENNET, R. O Declínio do Homem Público - As Tiranias da Intimidade. São Paulo: Editora Record, 2014.

SIZA, A. Imaginar a Evidência. Estação Liberdade, S. Paulo, 2012.

SOUZA, M.A. Posturas do Recife Imperial. Tese (Doutorado). Programa de Pós-Graduação em História, UFPE. Recife, 2002.

SOKOLOWSKI, R. Introdução à Fenomenologia. São Paulo: Edições Loyola, 2012.

\section{NOTAS}

1 Evidências, Intencionalidade, Essências, Presença, Ausência, Análise Fenomenológica, Olhar Fenomenológico, Antecipação, Imaginação e outros, são termos e conceitos trabalhados na Fenomenologia. Muitos desses termos constam na Tese. A Fenomenologia pode também fazer uso de outros métodos ou operações filosóficas com o fim de evidenciar. Pode trabalhar inclusive hipóteses, todavia, mais que comprová-las é seu objetivo evidenciar os seus elementos de estruturação. Para melhor entendimento, ver Sokolowski (2012).

2 Relacionamos tudo que se refere à forma arquitetônica do edifício ao tipo e à tipologia - o seu estudo. Tudo que se refere ao espaço urbano: sejam quadras, lotes, ruas e conjunto de edifícios; referimo-nos à morfologia ou morfologia urbana.Compartilham o mesmo entendimento autores como Rossi, Aymonino, Del Rio, Lamas.

${ }^{3} \mathrm{O}$ conceito de cultura urbana tem uma conotação menos antropológica. Está mais afeito às praticas sociais e formas espaciais locais. Representa a interação entre pessoas e espaço urbano.

${ }^{4}$ Diz respeito a uma forma tipológica híbrida. Uma Torre vertical destinada a usos habitacionais, serviços e outros usos, sobreposta sobre um edifício Base, ou seja, mais baixo e largo, ocupando área mais extensa e que constitui o pavimento Térreo e às vezes mais alguns. É um híbrido de duas formas ou tipos. O nome Torre/Pódio une tipo e função, pois o Pódio significa um edifício fechado e destinado exclusivamente para uso de garagem.

${ }^{5} \mathrm{O}$ conceito de modelo, como definido por Quatremère de Quincy, diz que diferentemente do tipo ele é reprodutível em sua forma e características físicas. O tipo é um conceito. Vide Rossi (1995).

6 Termo cunhado por Jane Jacobs e que significa o movimento de pessoas nas ruas e calçadas das cidades, vivenciando o espaço público. É um conceito valorativo e de qualidade da cidade e que tem relação, inclusive, com as soluções tipológicas de edifícios e morfológicas das quadras. Vide Jacobs (2000).

${ }^{7}$ Na Lei No. 2.590/1953 e na de No. 7.427/1961 a Prefeitura determinou o desenho de reocupação de quadras do Centro do Recife. Isso ficaria conhecido como Planos de Quadras do Centro. Os centros de alguns bairros também foram objeto desse instrumento urbanístico, como Encruzilhada, Casa Amarela, Afogados e Boa Viagem e eram chamados Centros Secundários. 


\section{Baltar (1951).}

9 Termo utilizado na Tese do Professor Baltar (1951).

10 Isso constituiu uma análise panorâmica, cujo foco, se delimitou ao entendimento sobre as relações entre público e privado, entre morfologia e tipologia. Para uma visão histórica e uma gênese sobre a legislação urbanística no Recife - vide Souza (2002).

${ }^{11}$ Foram os trabalhos de Da Matta (1997), Holanda (2014), Leitão (2009) e Sennet (2014).

12 Estes são alguns dos chamados 'parâmetros culturais de desenho urbano' desenvolvidos na Tese. Trata-se, especificamente, de tipologia e morfologia.

NOTA DO EDITOR $\left({ }^{*}\right)$ O conteúdo do artigo e as imagens nele publicadas são de responsabilidade do(s) autor(es). 